\title{
Durabilidad del hormigón: Acción del agua de mar sobre un cemento portland resistente a los sulfatos. Influencia de la adición de escorias y de cenizas volantes
}

\author{
DEMETRIO GASPAR-TEBAR y JOSE LUIS SAGRERA-MORENO \\ ICCET/CSIC \\ VICTORIANO GONZALEZ-VILA y MIGUEL MARIN-BOHORQUEZ \\ Cementos del Atlántico, S.A., Sevilla \\ ESPAÑA
}

Fecha de recepción: 30-X-91

\section{RESUMEN}

En este artículo, que forma parte de un Proyecto de Investigación del ICCET a largo plazo, se estudia la variación de las resistencias mecánicas - a flexotracciónde las probetas de mortero normalizado (1:3), de $1 \times 1 \times 6 \mathrm{~cm}$, mezclando un cemento portland resistente a los sulfatos y sus mezclas (cemento/adición $=85 / 15$ $65 / 35$ - 40/60 y 30/70, en peso), con una escoria, ceniza volante y arena silicea. Se someten a la acción de agua del mar artificial ASTM y de agua potable filtrada durante diversos periodos de tiempo (hasta 3 años para las dos primeras adiciones, y hasta 1 año para la tercera) después de la fase de curado (1 día en cámara húmeda y 21 días bajo agua potable filtrada).

Se estudia la evolución de la concentración iónica de los medios en donde han estado sumergidas dichas probetas de mortero, las características químicas de las nuevas fases sólidas formadas y la composición estructural de estas nuevas fases sólidas.

Por último, se da cuenta de los trabajos iniciados y de los resultados previos obtenidos -desde este punto de vistaen un lugar seleccionado del Puerto Autónomo de Huelva, en donde se están sometiendo a la acción del agua del mar diversas series de probetas de mortero y de hormigón, así como bloques de hormigón.

\section{SUMMARY}

This article, is part of a long time ICCET investigation programs studies the variation of the mechanical resistence to flexotraction $1: 3$ normaliced mortar with $1 \times 1 \times 6 \mathrm{~cm}$ dimension, using sulphate-resistent portland cement mixed with 15 - 35 - 60 and $70 \%$ parts of a furnace slag, a fly ash or silica sand. The samples were submited to the action of A.S.T.M. artificial sea water and filtered potable water during several time periods ( 3 years for the first and second addition and 1 year for the third) after the cured period (1 day at $100 \%$ R.H. and 21 days inside filtered potable water).

The evolution of the ionic concentration of the aggresive solutions were studied and also the new fases formed with its new structural composition. Finally, and account is given of the researches and first results about the bahaviour of the mortars and concretes made with two different industrial cements and submited to the natural sea water at a selected area of the marine Huelva-Port.

\section{PALABRAS CLAVE:}

DURABILIDAD HORMIGON-ACCION AGUA MARCEMENTOS-ESCORIAS-CENIZAS VOLANTES.

\section{INTRODUCCIÓN}

Con objeto de ampliar el conocimiento sobre el comportamiento mecánico-resistente de los cementos portland hidratados, y sobre todo de sus mezclas con adiciones naturales y artificiales sometidas a la acción del agua de mar, así como sobre el mecanismo de las reacciones que tienen lugar, se ha realizado este trabajo que forma parte de un Programa de Investigación del ICCET a desarrollar a largo plazo, tanto a escala de laboratorio como a escala real (1). 


\section{PARTE EXPERIMENTAL}

En esta comunicación se expone parte de los resultados obtenidos, hasta el momento, cuando las probetas de mortero (1:3) de $1 \times 1 \times 6 \mathrm{~cm}$ hechas con un cemento portland resistente a los sulfatos (cemento 2) -así como con las mezclas, que se reseñan en el apartado 2.2, de dicho cemento con una escoria granulada de horno alto, con una ceniza volante (ambas seleccionadas por sus características) y con arena silícea molida- se someten a la acción del agua de mar artificial ASTM D 1141-76 y del agua potable filtrada (series testigos) durante diversos períodos de tiempo, después de la fase de curado, determinando la evolución de las resistencias mecánicas a flexotracción de las probetas de mortero sumergidas en agua de mar artificial ASTM y en agua potable filtrada durante 56 días $3,6,9,12,18,24,30$ y 36 meses, después de la fase de curado (1 día en cámara húmeda y 21 días bajo agua potable filtrada) en el caso de las probetas elaboradas con el cemento y sus mezclas con la escoria y con la ceniza volante mencionadas, y durante 56 días 3 , 6,9 y 12 meses en el caso de las probetas fabricadas con las mezclas cemento/arena silícea molida.

Así mismo, en esta comunicación, se estudia la composición química de las nuevas fases sólidas formadas en los medios de curado (agua potable filtrada) y de conservación-ataque (agua de mar artificial ASTM y agua potable filtrada), en donde han estado sumergidas las probetas de mortero hechas con el cemento y sus mezclas con la escoria y la arena silícea mencionadas durante los primeros períodos de tiempo $(56,90,180$ y 360 días), así como la composición estructural tanto de dichas fases sólidas como de las fracciones enriquecidas extraidas de las probetas de mortero (pastas de cemento, de cemento/escoria y de cemento/arena molida) y la evolución de los contenidos de los iones $\mathrm{Ca}$ (II) y $\mathrm{Mg}$ (II), según los medios de conservación-ataque.

\subsection{Materiales utilizados}

\subsubsection{Cemento}

Se ha utilizado un cemento portland industrial resistente a los sulfatos que se ha designado cemento 2, cuya composición química y potencial calculada (Bogue), así como la superficie específica, se encuentran en la tabla 1.

En la figura 1 se incluyen los DRX del cemento y del residuo insoluble en ácido salícilico-metanol (zonas de las fases cristalinas correspondientes a los aluminatos).

\subsubsection{Adiciones}

De entre las adiciones estudiadas, en la primera etapa se han seleccionado una escoria granulada de horno alto, una ceniza volante y, además, arena silicea molida para utilizarla como control.

\section{a) Escoria}

Se ha empleado la escoria granulada de horno alto, cuyo análisis químico y difractograma de rayos $X$ se encuentran en la tabla 1 y en la figura 2.

\section{b) Ceniza volante}

Se ha empleado una ceniza volante, designada como C.V. (EN-1). Su composición química y diagrama de difracción de rayos $X$ se encuentran en la tabla 1 y en la figura 3.

\section{c) Arena}

Para fabricar las probetas de mortero (1:3) de $1 \mathrm{x}$ $1 \times 6 \mathrm{~cm}$ se ha usado la arena natural (El EspirdoSegovia) análoga a la empleada para preparar los morteros normalizados (UNE 80-101), con un contenido de $\mathrm{SiO}_{2}$ superior al $99 \%$. El tamaño de grano está comprendido entre 1 y $1,5 \mathrm{~mm}$. Por otra parte, esta arena se ha utilizado como adición al cemento, una vez molida hasta que ha pasado -toda ella- por un tamiz de $88 \mu \mathrm{m}$.

\subsubsection{Disoluciones agresivas y medios de curado $y$ de conservación}

Como disolución agresiva (medio de conservaciónataque) se ha utilizado agua de mar artificial ASTM y como medios de curado y de conservación agua potable filtrada.

\section{A) Agua de mar artificial ASTM}

El agua de mar artificial se ha preparado según el punto 6 de la norma ASTM D 1141-76. El contenido de los iones, que se citan a continuación, y el valor del $\mathrm{pH}$-determinados experimentalmente- son los siguientes:

Ca (II) $=0,521 \mathrm{~g} / \mathrm{l}<1,30 \times 10^{-2}$ moles/litro; $\mathrm{Mg}(\mathrm{II})=1,347 \mathrm{~g} / \mathrm{l}<>5,54 \times 10^{-2}$ moles/litro; $\mathrm{SO}_{4}$ (II) $=2,928 \mathrm{~g} / \mathrm{l}<>3,04 \times 10^{-2}$ moles/litro; $\mathrm{Cl}(\mathrm{l})=19,585 \mathrm{~g} / \mathrm{l}<>5,52 \times 10^{-2}$ moles/litro y $\mathrm{pH}=6,5$.

\section{B) Agua potable filtrada}

Como medios de curado y de conservación de las probetas de mortero se ha utilizado agua potable (Canal Isabel II, Madrid), una vez que ha pasado a través de un filtro cerámico. El contenido de los iones que se citan a continuación y el valor del pH -determinados experimentalmente- son los siguientes:

$\mathrm{Ca}(\mathrm{II})=0,005 \mathrm{~g} / \mathrm{l} ; \mathrm{Mg}$ (II) $=0,0016 \mathrm{~g} / \mathrm{l} ; \mathrm{SO}_{4}$ (II) $=$ $=0,003 \mathrm{~g} / \mathrm{l} ; \mathrm{Cl}(\mathrm{l})=0,007 \mathrm{~g} / \mathrm{l}$ y $\mathrm{pH}=7,1$. 
TABLA 1

Cemento 2, escoria y ceniza volante (EN-1). Características

\begin{tabular}{|c|c|c|c|}
\hline 1. Análisis químico (\%, en masa) & Cemento 2 & Escoria & Ceniza volante (EN-1) \\
\hline $\begin{array}{l}\text { Pérdida por calcinación } \\
\text { Residuo insoluble, } \mathrm{R}^{\prime} . \text {. } \\
\text { Dióxido de silicio, } \mathrm{SiO}_{2} \\
\text { Óxido de hierro (III), } \mathrm{Fe}_{2} \mathrm{O}_{3} \\
\text { Óxido de aluminio, } \mathrm{Al}_{2} \mathrm{O}_{3} \\
\text { Óxido de calcio, } \mathrm{CaO} \\
\text { Óxido de magnesio, } \mathrm{MgO} \\
\text { Trióxido de azufre, } \mathrm{SO}_{3} \\
\text { Manganeso (II) } \\
\text { Suma } \\
\mathrm{CaO} \text { libre }\end{array}$ & $\begin{array}{r}1,1 \\
0,2 \\
22,0 \\
4,1 \\
1,8 \\
67,9 \\
0,5 \\
2,3 \\
\text { n.d. } \\
99,9 \\
1,8\end{array}$ & $\begin{array}{r}0,4 \\
0,0 \\
35,2 \\
0,7 \\
17,0 \\
37,3 \\
6,3 \\
0,0 \\
0,8 \\
97,7\end{array}$ & $\begin{array}{r}2,8 \\
0,2 \\
46,1 \\
6,9 \\
36,4 \\
4,1 \\
1,9 \\
1,0 \\
\text { n.d. } \\
99,4\end{array}$ \\
\hline \multicolumn{4}{|l|}{ 2. Composición potencial (Bogue) } \\
\hline $\begin{array}{l}\mathrm{C}_{3} \mathrm{~S} \\
\mathrm{C}_{2} \mathrm{~S} \\
\mathrm{C}_{3} \mathrm{~A} \\
\mathrm{C}_{4} \mathrm{AF}\end{array}$ & $\begin{array}{r}75,6 \\
6,1 \\
0,0 \\
10,8\end{array}$ & & \\
\hline \multicolumn{4}{|l|}{ 3. Superficie especifica (Blaine) } \\
\hline $\mathrm{cm}^{2} / \mathrm{g}$ & 3.553 & & \\
\hline
\end{tabular}

n.d. = no determinado.

Cemento 2

RSM

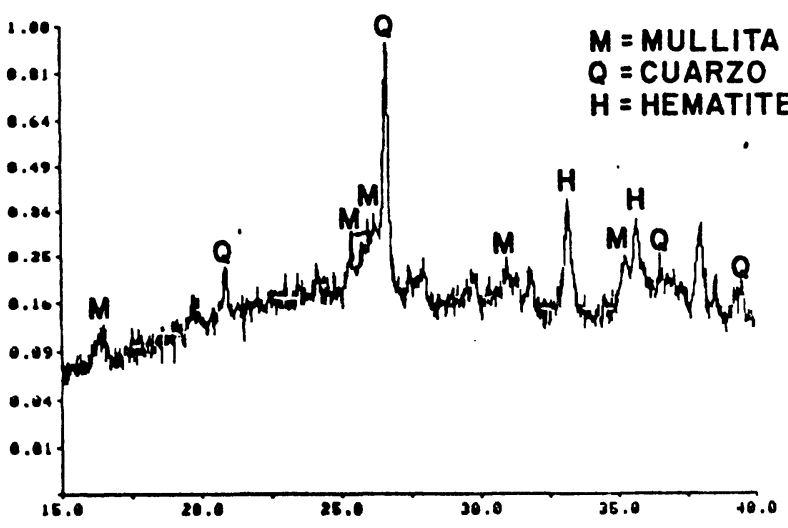

Fig. 1.-DRX del cemento 2 anhidro y del RSM.

Fig. 3.-DRX de la ceniza volante EN-1. 


\subsection{Preparación, curado y conservación de las probetas de mortero}

Con el cemento 2 y con sus mezclas cemento 2/escoria, cemento $2 /$ ceniza volante (EN-1) y cemento 2/arena molida $=85 / 15,65 / 35,40 / 60$ y $30 / 70$ (en peso), se han preparado las distintas series de probetas de mortero (1:3) de $1 \times 1 \times 6 \mathrm{~cm}$ como se señala en (2), habiendo utilizado la relación agua/cemento $=0,5$.

Las probetas se han curado 1 día en cámara húmeda (a $20 \pm 1^{\circ} \mathrm{C}$, con una humedad relativa superior a $90 \%$ y, a continuación, bajo agua potable filtrada (a $20 \pm 2^{\circ} \mathrm{C}$ ) durante 21 días. Posteriormente, se han sumergido 12 probetas/1 serie/1 cemento o una mezcla/1 edad en $800 \mathrm{ml}$ de agua potable filtrada y otras tantas series en agua de mar artificial ASTM, durante 56, 90, 180 y 360 días (1. etapa) y durante $18,24,30$ y 36 meses (2. etapa), solamente las probetas correspondientes al cemento 2 y a las mezclas cemento 2/escoria y cemento $2 /$ ceniza volante.

\subsection{Preparación de las nuevas fases sólidas}

Las nuevas fases sólidas, que se han formado en los medios en donde han estado sumergidas cada una de las series (12 probetas $/ 800 \mathrm{ml}$ ) de las probetas de mortero durante $56,90,180$ y 360 días (que, por el momento, se han estudiado), se han separado por filtración, una vez extraidas dichas probetas de mortero, y se han secado en una corriente de nitrógeno. De estas fases sólidas se ha hecho el estudio por DRX y, posteriormente, se ha determinado su composición química.

\subsection{Preparación de las fracciones enriquecidas}

De uno de los prismas de cada serie de probetas de mortero - ostraidas del agua de mar artificial ASTM y del agua potable filtrada, en donde han estado sumergidas durante los períodos de tiempo mencionados, una vez secos en un recinto aislado de la atmósfera - se ha separado del resto de dicha probeta la casi totalidad de la fracción correspondiente a la arena utilizada en su fabricación, por disgregación mecánica y con ayuda de un tamíz de $88 \mu \mathrm{m}$. De esta fracción, que se ha denominado "fracción enriquecida", de la que se ha eliminado la casi totalidad de la arena mencionada y en la que se encuentra la pasta de cemento o de las mezclas cemento/escoria y cemento/arena silícea molida, se ha hecho el estudio por DRX.

\section{RESULTADOS OBTENIDOS}

\subsection{Sistemas}

a) Cemento 2/adición (escoria o arena molida)agua potable filtrada.

b) Cemento 2/adición (escoria o arena molida)agua de mar artificial ASTM.

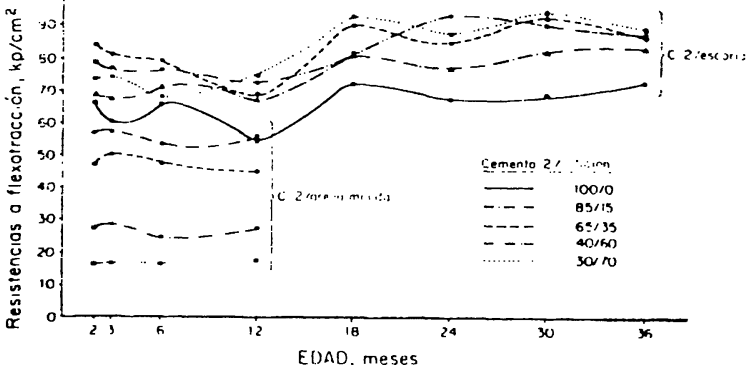

Fig. 4.-Sistemas: cemento 2/adición-agua potable filtrada. Evolución de las resistencias mecánicas, a flexotracción.

\subsubsection{Evolución de las resistencias mecánicas, a flexotracción}

En este apartado se estudia la evolución de las resistencias mecánicas, a flexotracción, de las diversas series de probetas de mortero (1:3) hechas con el cemento 2 y con sus mezclas con escoria, por una parte, y con arena silícea molida, por otra, en función de los tiempos de curado en agua potable filtrada $(1+21$ días), de conservación en agua potable filtrada y de conservación-ataque en agua de mar artificial.

a) Sistemas: cemento 2/escoria-agua potable filtrada, cemento 2/arena molida-agua potable filtrada

En la figura 4 se han representado los valores medios de las resistencias mecánicas a flexotracción, en $\mathrm{kp} / \mathrm{cm}^{2}$, de las diversas series de probetas de mortero (12 probetas por serie y por edad) sumergidas en agua potable filtrada después del período de curado, en función de los tiempos de curado $(1+21$ días) y de conservación (hasta tres años para las series hechas con cemento 2 y con sus mezclas con escoria y hasta un año para las series fabricadas con las mezclas cemento 2/arena molida).

En dicha figura se aprecia que la adición de la escoria estudiada favorece en todos los casos el comportamiento mecánico-resistente (a flexotracción) del cemento 2. Los valores óptimos se han obtenido con las series de probetas hechas con la mezcla que tiene la mayor cantidad de escoria (70 $\%$ en peso).

Por el contrario, la adición de arena silícea molida disminuye dicho comportamiento; esta disminución de las resistencias mecánicas es directamente proporcional a la cantidad de arena silícea molida en la mezcla utilizada para fabricar las probetas de mortero. Así, por ejemplo, las resistencias a flexotracción han pasado de $65 \mathrm{kp} / \mathrm{cm}^{2}$, a 56 días, a 55 $\mathrm{kp} / \mathrm{cm}^{2}$, a 360 días, para las series de probetas elaboradas con cemento 2, mientras que para las series hechas con la mezcla cemento 2/arena molida $=30 / 70$ (en peso) han pasado de $15 \mathrm{kp} / \mathrm{cm}^{2}, a$ 56 días, a $20 \mathrm{kp} / \mathrm{cm}^{2}$, a 360 días, lo que ha su- 


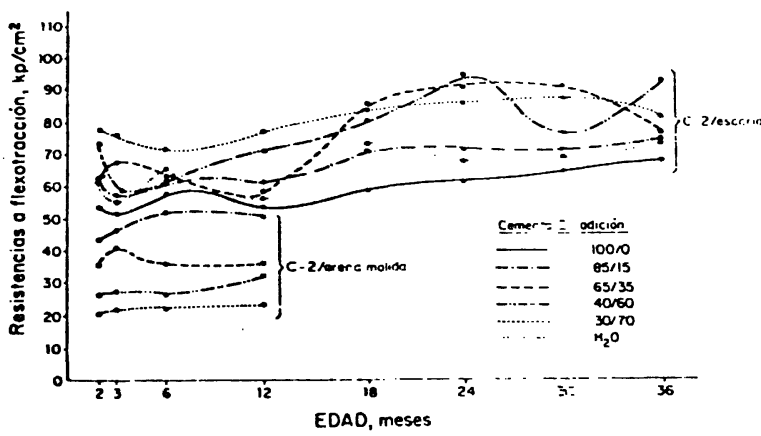

Fig. 5. - Sistemas: cemento 2/adición-agua de mar artificial ASTM. Evolución de las resistencias mecánicas, a flexotracción.

puesto una disminución de dichas resistencias superiores al $60 \%$.

b) Sistemas: cemento 2/escoria-agua de mar artificial ASTM, cemento 2/arena molida-agua de mar artificial ASTM

En la figura 5 se han representado los valores medios de las resistencias mecánicas a flexotracción, en $\mathrm{kp} / \mathrm{cm}^{2}$, de las diversas series de probetas de mortero (12 probetas por serie y por edad) sumergidas en agua de mar artificial ASTM después del período de curado, en función de los tiempos de curado (1 + 21 días) y de conservaciónataque (hasta tres años para las series hechas con cemento 2 y con sus mezclas con escoria y hasta un año para las series fabricadas con las mezclas cemento 2/arena molida).

En esta figura se observa que:

b.1.) La adición de la escoria estudiada al cemento 2 favorece, como en el caso anterior, el comportamiento mecánico-resistente (a flexotracción) de las probetas de mortero mencionadas cuando se someten a la acción del agua de mar artificial ASTM. Los valores mayores correponden -por regla generalen las distintas edades estudiadas, a las series de probetas elaboradas con la mezcla que tiene la mayor cantidad de escoria (70\%, en peso), seguidas de las hechas con la mezcla cemento $2 /$ escoria $=40 / 60$ (en peso).

b.2.) Por el contrario, las probetas fabricadas con las mezclas del cemento 2 con la arena silícea molida, sumergidas en agua de mar artificial ASTM, presentan valores menores -tanto menores, cuanto mayor es la cantidad de arena silícea molida- que los de las series hechas con cemento 2 .

b.3.) Las resistencias mecánicas a flexotracción de las series de probetas hechas con cemento 2 y sumergidas en agua de mar artificial ASTM son inferiores, con tendencia a igualarse conforme se incrementa el tiempo de conservación-ataque, que las correspondientes a las series análogas conservadas en agua potable filtrada.

b.4.) Las resistencias mecánicas (flexotracción) de las series de probetas hechas con la mezcla cemento $2 /$ escoria $=85 / 15$ (en peso) sumergidas en agua de mar artificial ASTM son inferiores, o del mismo orden, que las de las series análogas elaboradas con cemento 2 conservadas en agua potable filtrada, mientras que las de las series fabricadas con las mezclas que tienen 35 y $60 \%$ de escoria (en peso) son ligeramente inferiores a 6 meses y superiores en las edades restantes. Las resistencias mecánicas (flexotracción) de las series hechas con la mezcla que tiene el mayor contenido de escoria (70 $\%$ en peso) son superiores a todas las edades.

\subsubsection{Estudio de la concentración iónica}

En este apartado se da cuenta de la evolución del contenido de iones $\mathrm{Ca}$ (II) en el agua potable filtrada y de los iones $\mathrm{Ca}$ (II) y $\mathrm{Mg}$ (II) en el agua de mar artificial ASTM, en donde han estado sumergidas las diversas series de probetas de mortero durante 56, 90, 180 y 360 días, así como en la nueva fase sólida formada en dichos medios.

\section{a) Evolución del contenido de iones Ca (II)}

\section{a.1.) Sistemas: cemento 2/escoria-agua potable filtrada, cemento 2/escoria-agua de mar artificial ASTM}

Tanto en los medios de curado (agua potable filtrada), como de conservación (agua potable filtrada) y de conservación-ataque (agua de mar artificial ASTM) en donde han estado sumergidas las diversas series de probetas hechas con el cemento 2 y con sus mezclas con la escoria estudiada, se produce un incremento de los iones $\mathrm{Ca}$ (II) y la formación de una fase sólida.

\section{a.1.1.) Sistemas: cemento 2/escoria-agua potable filtrada}

El aumento de Ca (II) que aparece en el medio de conservación (agua potable filtrada), en donde se han sumergido las probetas de mortero, procede, fundamentalmente, de la disolución de parte del $\mathrm{Ca}(\mathrm{OH})_{2}$ - cuya solubilidad en agua a $20^{\circ} \mathrm{C}$ es $1,230 \mathrm{~g} / /(3)<>1,66 \times 10^{-2}$ moles/litro- formado en las mencionadas probetas de mortero como consecuencia de las reacciones de hidratación de la fracción clinker, y que no haya reaccionado con la escoria, según la reacción $(A)$ : (A) $\begin{aligned} \mathrm{Ca}(\mathrm{OH})_{2} \text {.sólido } \mathrm{H}_{2} \mathrm{O} & -\mathrm{Ca}(\mathrm{OH})_{2} \text {. disuelto } \mathrm{H}_{2} \mathrm{O}- \\ & \rightarrow \mathrm{Ca} \text { (II) }+2 \mathrm{OH} \text { (I) }\end{aligned}$

dando lugar además a un incremento de los iones 
$\mathrm{OH}(\mathrm{l}) \mathrm{y}$, por tanto, del valor del $\mathrm{pH}$, llegando a alcanzar valores superiores a 11.

Las cantidades de $\mathrm{Ca}(\mathrm{OH})_{2}$ disuelto son función de las que se formen en las mencionadas reacciones de hidratación que, a su vez, dependen de las mezclas cemento 2/escoria utilizadas en la fabricación de las diversas series de probetas de mortero. Parte del $\mathrm{Ca}(\mathrm{OH})_{2}$ formado reacciona con la escoria dando los compuestos de calcio correspondientes y otra parte experimenta, en las probetas, la reacción de carbonatación.

$\mathrm{El} \mathrm{Ca}(\mathrm{OH})_{2}$ disuelto (parte) reacciona, en medio básico fuerte, con el $\mathrm{CO}_{2}$ disuelto en el agua, según el equilibrio (B), precipitando $\mathrm{CaCO}_{3}$ - como calcita y aragonito, o como calcita, de acuerdo con las condiciones del medio- por alcanzarse el Ps $(4,8$ $\left.\times 10^{-9}\right)$, dando lugar a la formación de la nueva fase sólida según:

(B) $\mathrm{Ca}$ (II) $+2 \mathrm{OH}(\mathrm{I})+\mathrm{CO}_{2}-\mathrm{CaCO}_{3}$.sólido $+\mathrm{H}_{2} \mathrm{O}$

produciéndose una disminución junto con la de $\mathrm{Ca}$ (II) de los iones $\mathrm{OH}$ (I) y por consiguiente del valor del $\mathrm{pH}$.

En la zona rayada de la figura 6 -en donde se han representado los valores correspondientes a las cantidades de $\mathrm{Ca}(\mathrm{OH})_{2}$ disuelto [Ca (II) presente en la disolución y $\mathrm{Ca}$ (II) en la fase sólida] para 56 días (gráfica inferior) y para 360 días (gráfica superior) - se observa que las cantidades de $\mathrm{Ca}$ (II) $<>$ $<\mathrm{Ca}(\mathrm{OH})_{2}$ disuelto experimentan una disminución exponencial conforme lo hace la cantidad de clinker, o aumenta la de escoria en la mezcla utilizada para fabricar las diversas series de probetas de mortero.

Las mencionadas cantidades disueltas son menores que las correspondientes teóricas -calculadas a partir del $\mathrm{Ca}$ (II) encontrado en la disolución y en la nueva fase sólida formada en el medio en donde han estado sumergidas las probetas hechas con cemento 2- debido a las reacciones que tienen lugar entre la escoria y el $\mathrm{Ca}(\mathrm{OH})_{2}$ naciente formado, como consecuencia de los procesos de hidratación del cemento.

\section{a.1.2.) Sistemas: cemento 2/escoria-agua de mar artificial ASTM}

Cuando el medio de conservación-ataque de las series de probetas es el agua de mar artificial ASTM el equilibrio (A) se ve afectado por la presencia de iones presentes en el agua de mar artificial no comunes, distintos del $\mathrm{Ca}$ (II) de un modo especial, y -además-por la existencia de otros iones - compuestos que dan lugar a reacciones de precipitación con los iones Ca (II) o con los iones $\mathrm{OH}(\mathrm{I})$ del mencionado equilibrio (A), como sucede con los iones $\mathrm{Mg}$ (II), $\mathrm{SO}_{4}$ (II) y con el $\mathrm{CO}_{2}$, según:

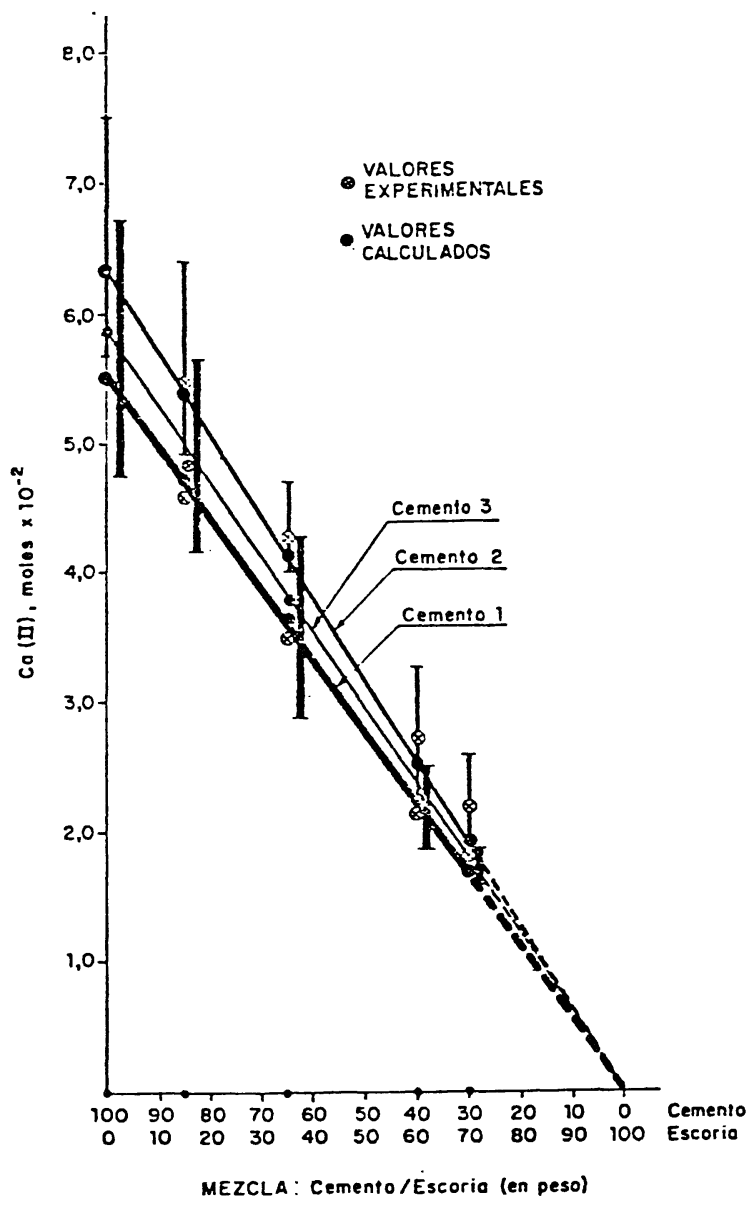

Fig. 6.-Sistemas: cemento 2/escoria-agua potable filtrada. Cemento 2/escoria-agua de mar artificial ASTM. Evolución del contenido de: $\mathrm{Ca}$ (II) $<>\mathrm{Ca}(\mathrm{OH})_{2}$ disuelto.

(B) $\mathrm{Ca}$ (II) $+2 \mathrm{OH}$ (I) $+\mathrm{CO}_{2}-\mathrm{CaCO}_{3}$. sólido $+\mathrm{H}_{2} \mathrm{O}$

(C) $\mathrm{Ca}$ (II) $+\mathrm{SO}_{4}$ (II) $+2 \mathrm{H}_{2} \mathrm{O}-\mathrm{CaSO}_{4} \cdot 2 \mathrm{H}_{2} \mathrm{O}$ sólido

(D) $\mathrm{Mg}(\mathrm{II})+2 \mathrm{OH}(\mathrm{I})-\mathrm{Mg}(\mathrm{OH})_{2}$.sólido

Como consecuencia de estas reacciones se produ$c e$, en un determinado grado, la disminución de iones $\mathrm{Ca}$ (II) y $\mathrm{OH}$ (I) en el medio, favoreciendo, así mismo, la disolución de los compuestos de calcio y de un modo especial del $\mathrm{Ca}(\mathrm{OH})_{2}$, así como el avance de las reacciones de hidratación; fenómenos que, a su vez y para cada mezcla, son función del tiempo de conservación-ataque de las probetas, como se ha probado por DRX. Todos estos fenómenos hacen que las cantidades de $\mathrm{Ca}(\mathrm{OH})_{2}$ disuelto en los sistemas cemento 2/escoria-agua de mar artificial ASTM sean superiores a las correspondientes a los sistemas cemento 2/escoria-agua potable filtrada.

Los compuestos sólidos formados dan lugar a una nueva fase sólida, en la que se han detectado por DRX los picos de los compuestos cristalinos calcita, aragonito, brucita y -en algunos casos- yeso. 


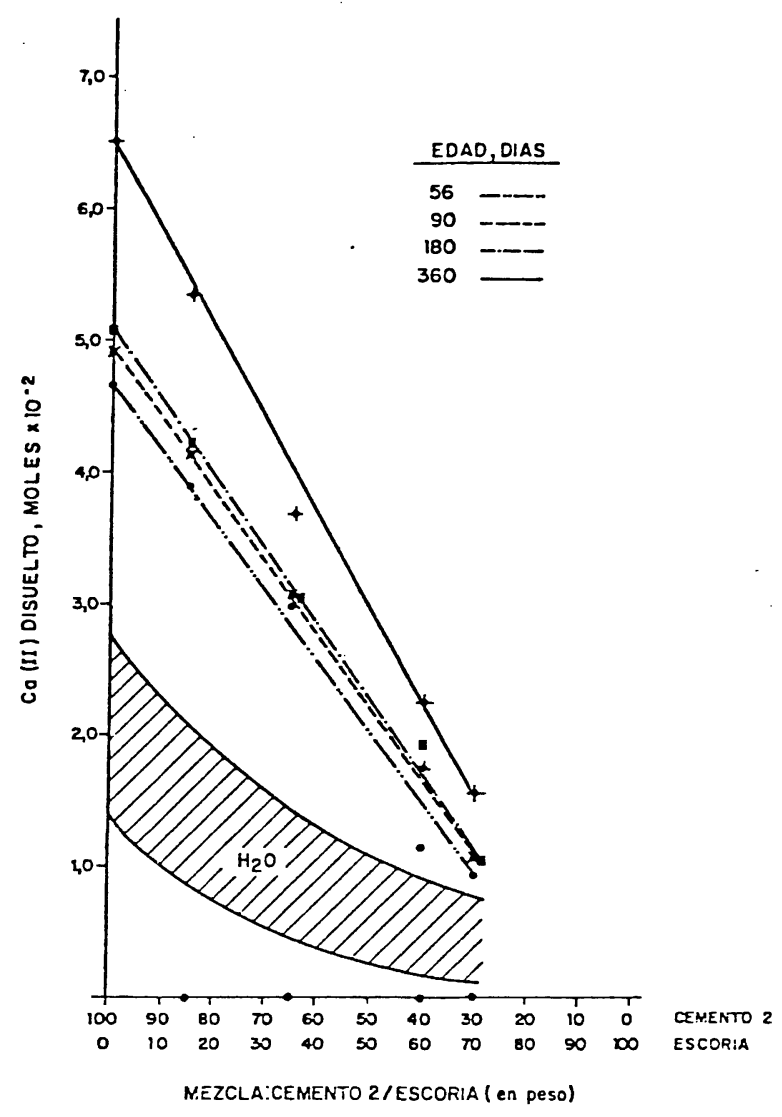

Fig. 7.-Sistemas: cemento 2/escoria-agua de mar artificial ASTM. Evolución del contenido de Ca (II) total.

Las cantidades de $\mathrm{Ca}$ (II) $<>\mathrm{Ca}(\mathrm{OH})_{2}$ disuelto, que se encuentran en la disolución y en la nueva fase sólida, en cada caso, disminuyen bruscamente conforme lo hace el contenido de cemento en la mezcla utilizada para fabricar las diversas series de probetas de mortero, como se aprecia en la figura 6 , en donde se han representado, para cada edad, los valores del $\mathrm{Ca}(\mathrm{OH})_{2}$ disuelto [ $\mathrm{Ca}$ (II) en la disolución + $\mathrm{Ca}$ (II) en la fase sólida] correspondientes a las diversas series de probetas.

Si además del Ca (II) mencionado se considera el $\mathrm{Ca}$ (II) que existe en el agua de mar artificial $\left(1,04 \times 10^{-2} / 800 \mathrm{ml}\right)-\mathrm{s}$ decir el $\mathrm{Ca}$ (II) total presente en la disolución más el de la fase sólidase aprecia que para cada edad, figura 7 , dichas cantidades se encuentran alineadas, prácticamente, en una recta que une los puntos correspondientes al $\mathrm{Ca}(\mathrm{OH})_{2}$ disuelto procedente de las series de probetas hechas con cemento 2 sin adición de escoria, más el del agua de mar, en ordenadas, y el de la mezcla teórica cemento 2/escoria $=0 / 100$ (cuando no hay cemento) en abscisas; se trata, por consiguiente, de un fenómeno aditivo.

Este proceso se ha confirmado en otros dos sistemas, correspondientes a otros dos cementos de características estructurales distintas, como se puede observar en la figura 7 .
En dicha figura 7 (en la que se encuentran los valores medios experimentales y teóricos para cada mezcla y para las cuatro edades consideradas por el momento, así como los valores máximos y mínimos para cada edad) se aprecia que las cantidades de $\mathrm{Ca}$ (II) son función de la cantidad de cemento en la mezcla utilizada para fabricar las diversas series de probetas de mortero.

\section{a.2.) Sistemas: cemento 2/arena molida-agua potable filtrada, cemento 2/arena molida-agua de mar artificial ASTM}

Del mismo modo que en el caso del sistema anterior, el contenido de $\mathrm{Ca}$ (II) se ha incrementado tanto en los medios de curado (agua potable filtrada), como de conservación (agua potable filtrada) y de conservación-ataque (agua de mar artificial ASTM), en donde han estado sumergidas las diversas series de probetas de mortero hechas con las mezclas cemento 2/arena silícea molida. Además, ha tenido lugar la formación de una nueva fase sólida.

\section{a.2.1.) Sistemas: cemento 2/arena molida-agua potable filtrada}

El incremento de $\mathrm{Ca}$ (II) en el agua potable filtrada, en donde se han sumergido las diversas series de probetas de mortero fabricadas con las cuatro mezclas mencionadas, así como el presente en la nueva fase sólida, se debe, de un modo especial, a la disolución parcial del $\mathrm{Ca}(\mathrm{OH})_{2}$ generado en las reacciones de hidratación de la fracción clinker, de acuerdo con la reacción (A).

Las cantidades de $\mathrm{Ca}$ (II) $<>\mathrm{Ca}(\mathrm{OH})_{2}$ disuelto, fundamentalmente, dependen del tiempo de conservación de las probetas, produciéndose un incremento conforme aumenta dicho tiempo, como se puede apreciar en la tabla 2, en la que se han incluído los valores correspondientes a 56 días (edad menor) y a 360 días (edad mayor), así como el valor medio para cada mezcla correspondiente a las cuatro edades estudiadas.

Los valores del $\mathrm{Ca}$ (II) total puesto en juego en los medios en donde han estado las series de probetas hechas con las distintas mezclas del cemento 2 con la arena silícea molida, son del mismo orden que los correspondientes al medio en donde han estado las probetas elaboradas con cemento 2 .

En estos sistemas se ha producido un incremento del valor del $\mathrm{pH}$, que es superior a 12 en la mayoría de los casos. Así mismo, se ha formado una nueva fase sólida por precipitación del $\mathrm{Ca}$ (II) con el $\mathrm{CO}_{2}$-en medio básico fuerte- como $\mathrm{CaCO}_{3}$, en forma de calcita -on su mayor parte-y de aragonito.

\section{a.2.2.) Sistemas: cemento 2/arena molida-agua de mar artificial ASTM}


Del mismo modo que en el caso del sistema anterior, se ha producido un incremento de $\mathrm{Ca}$ (II) en el agua de mar artificial ASTM y, además, se ha formado una nueva fase sólida en la que existen compuestos de $\mathrm{Ca}$ (II), entre otros, como se verá más adelante.

Las cantidades de $\mathrm{Ca}$ (II) total [Ca (II) en la disolución + Ca (II) en la fase sólida] experimentan un aumento conforme lo hace el tiempo de conservación-ataque (tabla 3, en la que se han incluído los valores de la edad menor - 56 días - y máxima -360 días-, asi como el valor medio para cada mezcla correspondiente a las cuatro edades).
En estos sistemas (cemento 2/arena molida, agua de mar artificial ASTM) las cantidades medias de $\mathrm{Ca}$ (II) $<>\mathrm{Ca}(\mathrm{OH})_{2}$ disuelto, fundamentalmente, son del mismo orden que las correspondientes al sistema cemento 2 (cemento 2/adición $=100 / 0$ )agua de mar artificial ASTM, excepto para el caso de las series de probetas hechas con las mezclas que tienen los menores contenidos de clinker (40 y $30 \%$, en peso).

b) Evolución del contenido de iones Mg (II)

b.1.) Sistemas: cemento 2/escoria-agua de mar artificial ASTM, cemento 2/arena molida-agua de mar artificial ASTM

TABLA 2

Sistemas: cemento 2/arena molida-agua potable filtrada Evolución del contenido de Ca (II)

\begin{tabular}{|c|c|c|c|}
\hline $\begin{array}{c}\text { Mezcla (en peso): } \\
\text { cemento 2/arena }\end{array}$ & $\begin{array}{c}\text { Edad, días } \\
\mathbf{1 . 2} \text { edad } \\
\mathbf{4 . 2} \text { edad }\end{array}$ & $\begin{array}{c}\text { Ca (II), total } \\
\text { moles } \times \mathbf{1 0}^{-2}\end{array}$ & $\begin{array}{c}\text { Valor medio } \\
\text { cuatro edades } \\
\text { moles } \times \mathbf{1 0}^{-2}\end{array}$ \\
\hline $100 / 0$ & 56 & 1,23 & 2,01 \\
\hline $85 / 15$ & 360 & 2,91 & 2,09 \\
\hline $65 / 35$ & 56 & 1,55 & 2,58 \\
\hline $40 / 60$ & 360 & 2,50 & 2,40 \\
\hline $30 / 70$ & 360 & 3,59 & 1,71 \\
\hline
\end{tabular}

TABLA 3

Sistemas: cemento 2/arena molida-agua de mar artificial ASTM Evolución del contenido de Ca (II)

\begin{tabular}{|c|c|c|c|}
\hline $\begin{array}{c}\text { Mezcla (en peso): } \\
\text { cemento 2/arena }\end{array}$ & $\begin{array}{c}\text { Edad, dias } \\
\mathbf{1 . 2} \text { edad } \\
\mathbf{4 . 2} \text { edad }\end{array}$ & $\begin{array}{c}\text { Ca (II), total } \\
\text { moles } \times \mathbf{1 0}^{-2}\end{array}$ & $\begin{array}{c}\text { Valor medio } \\
\text { cuatro edades } \\
\text { moles } \times \mathbf{1 0}^{-2}\end{array}$ \\
\hline $100 / 0$ & 56 & 5,69 & 6,35 \\
\hline $85 / 15$ & 360 & 7,57 & 6,10 \\
\hline $65 / 35$ & 56 & 5,74 & 6,72 \\
\hline $40 / 60$ & 560 & 5,74 & 5,88 \\
\hline $30 / 70$ & 360 & 5,76 & \\
\hline
\end{tabular}


El contenido de $\mathrm{Mg}$ (II) del agua de mar artificial ASTM $\left(4,43 \times 10^{-2}\right.$ moles $\left./ 800 \mathrm{ml}\right)$ en donde han estado sumergidas las probetas de mortero durante las cuatro primeras edades estudiadas (por el momento), hechas con el cemento 2 y con la mezcla cemento $2 /$ escoria $=85 / 15$ (en peso), ha desaparecido, prácticamente, habiendo precipitado como $\mathrm{Mg}(\mathrm{OH})_{2}$ tanto en las probetas de mortero como en la disolución, dando lugar -en estos casos- a la nueva fase sólida, junto con la calcita y el aragonito, como se ha probado por DRX (4).

Del mismo modo, en los diversos sistemas cemento 2/arena molida $=85 / 15,65 / 35,40 / 60$ y 30/70 (en peso) el Mg (II) ha desaparecido, prácticamente, del agua de mar artificial, habiendo precipitado como $\mathrm{Mg}(\mathrm{OH})_{2}$ en los dos primeros casos, formando la nueva fase sólida - junto con la calcita, el aragonito, la halita y la gehlenita - en cantidades análogas a las del medio en donde han estado las probetas elaboradas con cemento 2 y en las probetas de mortero, como se ha probado por DRX (del estudio correspondiente se dará cuenta en otras publicaciones); en los casos restantes no se ha detectado por DRX.

El Mg (II) que existe en el agua de mar artificial reacciona a $\mathrm{pH}>10$ con los iones $\mathrm{OH}(\mathrm{I})$ del equilibrio (A), según la reacción (D), precipitando $\mathrm{Mg}(\mathrm{OH})_{2}$ por cumplirse $[\mathrm{Mg}(\mathrm{II})] \times[\mathrm{OH}(\mathrm{I})]^{2}>\mathrm{Ps}$ $\left(1,8 \times 10^{-11}\right)$; esta reacción lleva consigo una disminución del $\mathrm{pH}$.

En los medios $(800 \mathrm{ml})$ en donde han estado sumergidas las series de probetas hechas con cemento 2, con las mezclas cemento 2/escoria = $=85 / 15$ y cemento 2/arena molida $=85 / 15,65 / 35$ y 40/60 (en peso), el pH es mayor de 10,5 (por regla general, es superior a 11), debido a la cantidad de $\mathrm{Ca}(\mathrm{OH})_{2}$ disuelto y a la influencia de las características de la adición (escoria y arena silícea molida). Por ello, ha tenido lugar la reacción (D), habiéndose detectado los picos del compuesto cristalino brucita en los DRX realizados de las nuevas fases sólidas. En dichas fases sólidas el Mg (II) se encuentra en cantidades menores de $2,4 \times 10^{-2}$ moles y en las fases líquidas en cantidades menores de $0,6 \times 10^{-2}$ moles; el resto ha precipitado en las probetas de mortero como brucita (5), según el equilibrio $(E)$ :

(E) $\mathrm{Mg}(\mathrm{II})+\mathrm{Ca}(\mathrm{OH})_{2}$.disuelto- $\mathrm{Mg}(\mathrm{OH})_{2}$. sólido $+\mathrm{Ca}(\mathrm{II})$

$$
\text { disolución probeta probeta }
$$

de tal modo que por cada mol de iones $\mathrm{Mg}$ (II) que ha precipitado, pasa al medio otro de $\mathrm{Ca}$ (II), el cual puede reaccionar con los compuestos de la escoria que se encuentra en las probetas o pasar a la disolución.

Por el contrario, en el agua de mar artificial ASTM en donde han estado sumergidas las series de probetas de mortero fabricadas con las mezclas cemento 2 /escoria $=65 / 35,40 / 60$ y $30 / 70$ (en peso)

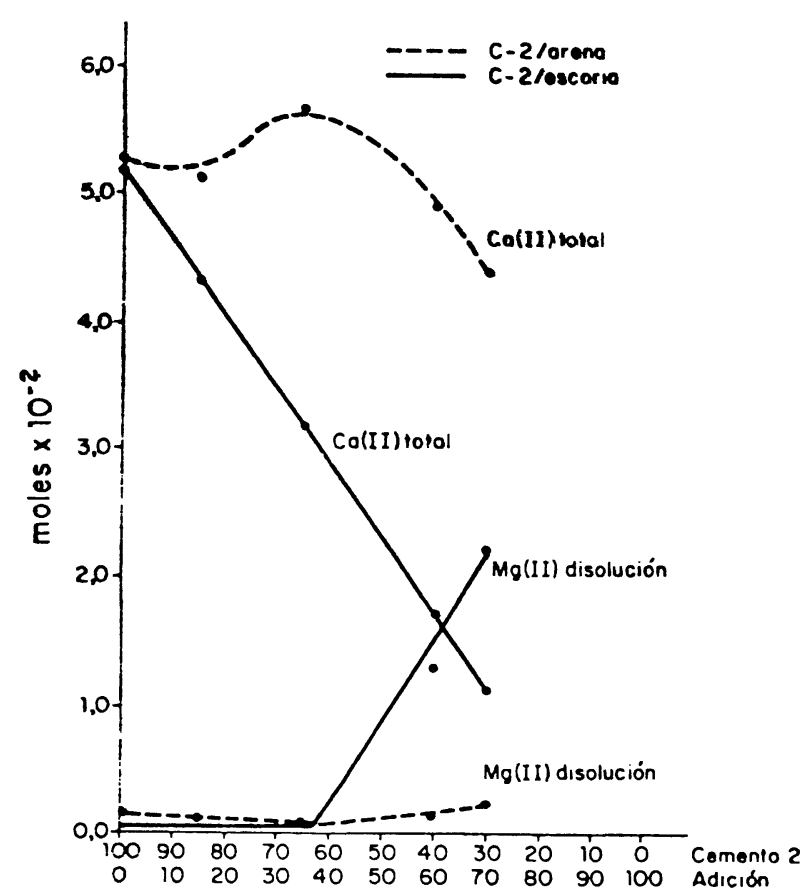

Fig. 8.-Sistemas: cemento 2/adición-agua de mar artificial ASTM. Evolución del contenido de $\mathrm{Ca}$ (II) y de $\mathrm{Mg}$ (II).

no ha precipitado en la disolución (no se ha detectado en la nueva fase sólida) por no darse las condiciones adecuadas $(\mathrm{pH}<10)$ y no alcanzarse el Ps, así como en el caso de la serie de probetas hecha con la mezcla cemento 2/arena $=30 / 70$ (en peso). Dicho ion $\mathrm{Mg}$ (II) se encuentra en la disolución en cantidades inferiores a $0,6 \times 10^{-2}$ moles $/ 800$ $\mathrm{ml}$ en donde han estado las probetas hechas con la mezcla que tiene el $70 \%$ (en peso) de arena molida y en cantidades inferiores a $2,5 \times 10^{-2}$ moles $/ 800 \mathrm{ml}$ y superiores a $1,0 \times 10^{-2}$ moles $/ 800 \mathrm{ml}$ en donde se sumergieron las series de probetas fabricadas con las mezclas cemento 2/escoria = = 40/60 y $30 / 70$ (en peso); el resto de $\mathrm{Mg}$ (II) ha precipitado, en su mayor parte, en las probetas de mortero como brucita; otra parte -en cantidades menores de $0,3 \times 10^{-2}$ moles, no detectadas por DRX - se encuentra en la nueva fase sólida.

c) Evolución de los contenidos de $\mathrm{Ca}$ (II) y de $M g$ (II)

\section{c.1.) Sistemas: cemento 2/escoria-agua de mar artificial ASTM, cemento 2/arena molida-agua de mar artificial ASTM}

En la figura 8, en donde se ha representado la evolución de los contenidos medios - para cada mezcla, correspondientes a las cuatro primeras edades-de los iones $\mathrm{Ca}$ (II) $<>\mathrm{Ca}(\mathrm{OH})_{2}$ disuelto y Mg (II) del agua de mar artificial ASTM, en donde han estado sumergidas las series de probetas de mortero correspondientes a estos dos sistemas, se aprecia que ambos contenidos (que dependen de 
las características de la adición) están íntimamente relacionados, de tal modo que cuando uno disminuye el otro aumenta y viceversa, existiendo un punto de corte en el caso de la mezcla cemento/escoria $\approx 40 / 60$ (en peso), en donde tiene lugar el equilibrio iónico:

\section{Ca (II) que pasa a la disolución - Mg (II) que desaparece de la disolución.}

En los casos de las probetas hechas con las mezclas que tienen cantidades inferiores al $60 \%$ de escoria, las cantidades de $\mathrm{Ca}$ (II) son superiores a las de $\mathrm{Mg}$ (II), ya que se genera más $\mathrm{Ca}(\mathrm{OH})_{2}$ durante la hidratación, quedando libre, en parte, mayor cantidad que facilita la precipitación del $\mathrm{Mg}$ (II) y la disolución del $\mathrm{Ca}(\mathrm{OH})_{2}$; por el contrario, en los casos de las probetas fabricadas con mezclas que tienen cantidades superiores de escoria (70\%) se invierte el fenómeno, quedando en la disolución + en la nueva fase sólida contenidos mayores de $\mathrm{Mg}$ (II) que de $\mathrm{Ca}$ (II), por no darse las condiciones para que precipite el $\mathrm{Mg}$ (II) al no existir cantidad suficiente de iones $\mathrm{OH}(\mathrm{I})$. Los hechos mencionados influyen en el grado de resistencia química de los cementos.

En el caso de las mezclas cemento 2/arena molida no existe dicho punto de corte; las cantidades de $\mathrm{Ca}$ (II) oscilan entre $4,34 \times 10^{-2}$ moles $/ 800 \mathrm{ml}$ y $5,68 \times 10^{-2}$ moles $/ 800 \mathrm{ml}$, mientras que las de $\mathrm{Mg}$ (II) son menores de $0,25 \times 10^{-2}$ moles $/ 800 \mathrm{ml}$.

\subsubsection{Estudio de las nuevas fases sólidas por $D R X$}

En el agua potable filtrada y en el agua de mar artificial ASTM, en donde han estado sumergidas las distintas series de probetas de mortero durante $56,90,180$ y 360 días, se han formado nuevas fases sólidas en las que, por DRX, se han identificado los picos de los siguientes compuestos cristalinos:

\section{a) Sistemas: cemento 2/adición-agua potable filtrada}

En los DRX correspondientes a las nuevas fases sólidas formadas en el agua potable filtrada, en donde se han conservado las probetas de mortero hechas con cemento 2 y con cemento 2/arena molida $=85 / 15,65 / 35$ y $30 / 70$, en peso, en algunos casos se han detectado los picos de los compuestos cristalinos calcita y aragonito (los picos del aragonito son de menor intensidad que los de la calcita), mientras que en las nuevas fases sólidas formadas en el agua potable filtrada, en donde se sumergieron las diversas series de probetas de mortero fabricadas con las mezclas cemento $2 / 0 s-$ coria y con cemento 2/arena molida $=40 / 60$ y $30 / 70$, en peso en algunos casos únicamente se han detectado los picos de la calcita. b) Sistemas: cemento 2/adición-agua de mar artificial ASTM

En los DRX de las nuevas fases sólidas formadas en estos sistemas se han detectado los picos de los siguientes compuestos cristalinos:

b.1.) Calcita y aragonito en todos los casos estudiados, con intensidades distintas. Así, la intensidad de los picos de la calcita es mayor que la de los del aragonito en los DRX de las fases sólidas formadas, en donde se han sumergido las probetas hechas con cemento 2 con la mezcla cemento/escoria $=85 / 15$, en peso, y con las diversas mezclas cemento/arena molida; en estos casos las cantidades de $\mathrm{Ca}(\mathrm{OH})_{2}$ disuelto, fundamentalmente, son mayores de $4 \times 10^{-2}$ moles $/ 800 \mathrm{ml}$, las de $\mathrm{Mg}$ (II) en la disolución, prácticamente, nulas y el $\mathrm{pH}>10,5$.

Por el contrario, dicha intensidad de los picos de la calcita es menor que la de los picos del aragonito en los DRX de las fases sólidas formadas en el agua de mar artificial ASTM, en donde han estado las probetas de mortero hechas con las mezclas cemento 2/escoria $=40 / 60$ y $30 / 70$ (en peso). En estos casos, el contenido de Ca (II) en la disolución + en la fase sólida es superior a 1,3 × $10^{-2}$ moles $/ 800$ $\mathrm{ml}$, e inferior a $3,5 \times 10^{-2}$ moles $/ 800 \mathrm{ml}$, el de $\mathrm{Mg}$ (II) en la disolución es mayor de $1,1 \times 10^{-2}$ moles $/ 800 \mathrm{ml}$ y menor de $3,1 \times 10^{-2}$; el valor del $\mathrm{pH}$ es mayor de 7,8 y menor de 8,0 .

b.2.) Brucita en las fases sólidas formadas en el agua de mar artificial ASTM, en donde se han sumergido las series de probetas fabricadas con cemento 2 , con las mezclas cemento 2/escoria $=85 / 15$ y cemento 2/arena molida = 85/15, 65/35 y 40/60 (en algunos casos), en peso. En estos casos el pH es superior a 10,5 ; las concentraciones de $\mathrm{Ca}$ (II) son mayores de $3,5 \times 10^{-2}$ moles $/ 800 \mathrm{ml}$ y nula, prácticamente, la de $\mathrm{Mg}$ (II).

b.3.) Halita y gehlenita en el agua de mar artificial ASTM, en donde han estado las series de probetas hechas con las mezclas estudiadas del cemento 2 y arena molida.

b.4.) Yeso, en algunos casos.

\subsubsection{Estudio de las fracciones enriquecidas por DRX}

En las fracciones enriquecidas extraídas de uno de los prismas de cada serie de probetas de mortero hechas con el cemento 2 y con las mezclas cemento 2/escoria y cemento 2/arena molida estudiadas, sumergidas durante $56,90,180$ y 360 días en agua potable filtrada y en agua de mar artificial ASTM se ha hecho el estudio por DRX, habiendo identificado los picos de los siguientes compuestos cristalinos: 
a) Sistemas: cemento 2/adición-agua potable filtrada

a.1.) Ettringita, en todos los DRX. La intensidad de los picos de este compuesto disminuye, por regla general, en los DRX de las fracciones extraídas de las series de probetas hechas con las mezclas cemento 2/escoria conforme lo hace el contenido de cemento. En todos los casos esta intensidad es menor que la de los diagramas de las fracciones extraídas de las probetas de mortero fabricadas con cemento 2 (6); por el contrario, en los DRX de las fracciones extraídas de las probetas elaboradas con las diversas mezclas cemento 2/arena molida, dicha intensidad es igual o ligeramente mayor.

a.2.) Yeso, en algunos DRX.

a.3.) Portlandita, en todos los diagramas (excepto en los correspondientes a la mezcla cemento 2/adición $=30 / 70$, en peso, para 360 días) . La intensidad de los picos correspondientes disminuye en los DRX conforme la hace la cantidad de clinker en la mezcla utilizada para fabricar las probetas de mortero. Esta disminución es mayor en los DRX de las fracciones extraídas de las probetas hechas con las mezclas cemento 2/escoria, que en los de las probetas análogas fabricadas con cemento 2/arena molida, como consecuencia de las reacciones que tienen lugar entre la escoria y el $\mathrm{Ca}(\mathrm{OH})_{2}$ naciente generado en las reacciones de hidratación. Este fenómeno está de acuerdo con la menor cantidad de $\mathrm{Ca}$ (II) $<>\mathrm{Ca}(\mathrm{OH})_{2}$ disuelto, como se ha mencionado en 3.1.2.

a.4.) Calcita, en todos los DRX.

a.5.) Cuarzo- $\alpha$, en todos los DRX. Los picos de este compuesto corresponden a la fracción arena utilizada para preparar las probetas de mortero y, además, a las distintas cantidades de arena silícea molida empleada como adición en las mezclas cemento 2/arena; las intensidades de los picos de este compuesto reflejan cuantitativamente la cantidad de arena utilizada como adición.

b) Sistemas: cemento 2/adición-agua de mar artificial ASTM

b.1.) Ettringita, prácticamente, en todos los DRX. La intensidad de los picos de este compuesto es del mismo orden en los diagramas de las fracciones extraídas de las probetas hechas con la mezcla cemento 2/escoria $=85 / 15$ (en peso) que la correspondiente a los DRX de las muestras de las series fabricadas con cemento 2 y menor en los casos restantes (DRX de las probetas elaboradas con las mezclas con escoria que tienen $35 \%, 60 \%$ y $70 \%$, en peso).
Dicha intensidad es del mismo orden, o ligeramente mayor, en los diagramas de las fracciones extraídas de las diversas series de probetas hechas con las mezclas cemento 2/arena molida que la de los DRX correspondiente a las probetas fabricadas con cemento 2.

b.2.) Yeso en los DRX de las muestras extraídas de las series de probetas hechas con cemento 2 con las mezclas cemento 2/escoria = $85 / 15,65 / 35,40 / 60$ y $30 / 70$, en peso (solo en dos casos y, además, los picos tienen pequeña intensidad), y con todas las mezclas cemento 2/arena molida, debido a la formación de $\mathrm{CaSO}_{4} \cdot 2 \mathrm{H}_{2} \mathrm{O}$ por reacción de los iones $\mathrm{SO}_{4}$ (II) del agua de mar artificial ASTM con los iones $\mathrm{Ca}$ (II) del $\mathrm{Ca}(\mathrm{OH})_{2}$ presente en las probetas de mortero. Parte de este yeso al reaccionar con los aluminatos de calcio hidratados del cemento da lugar a la formación de ettringita.

La intensidad de los picos del yeso es mayor en los diagramas de las fracciones extraídas de las probetas fabricadas con las mezclas cemento 2/arena molida, de un modo especial las de dos mezclas que tienen 60 y 70 $\%$, en peso, que - a su vez - es mayor que la correspondiente a los diagramas de las muestras de las mezclas cemento 2/escoria.

b.3.) Portlandita, en todos los DRX de las fracciones extraidas de las probetas hechas con cemento 2, con las mezclas cemento 2/escoria $=85 / 15$ y $65 / 35$ (en peso) y con todas las mezclas cemento 2/arena molida (excepto en 4 casos de 20). La intensidad de los picos de este compuesto disminuye conforme lo hace la cantidad de cemento en la mezcla y, como en los casos anteriores, depende - de un modo especial-de las características de las adición utilizada (escoria y arena silícea molida) y de la presencia de iones $\mathrm{Mg}$ (II) en el agua de mar artificial ASTM.

b.4.) Calcita, en todos los DRX.

b.5.) Brucita, en todos los DRX. La intensidad de los picos de las fracciones extraídas de las series de probetas hechas con las mezclas cemento $2 /$ escoria $=65 / 35,40 / 60$ y $30 / 70$ (en peso) y cemento 2/arena molida $=40 / 60$ y 30/70 (en peso), fundamentalmente, es mayor que la correspondiente a la de las series de probetas fabricadas con cemento 2. Estos procesos se corresponden con las cantidades de $\mathrm{Mg}$ (II) en el aguá de mar artificial ASTM y en la nueva fase sólida, como se ha señalado en el apartado 3.1.2.

b.6.) Sal de Friedel, en los DRX de las fracciones enriquecidas extraídas de las series de probetas fabricadas con las mezclas cemento 
2/escoria $=65 / 35,40 / 60$ y $30 / 70$ (en peso). En la formación de la sal de Friedel, en estos sistemas, han influido las características y cantidad de la escoria utilizada.

b.7.) Cuarzo- $\alpha$, en todos los DRX. La intensidad de los picos de este compuesto correspondiente a la fracción de arena utilizada para preparar las probetas de mortero $y$, además, a las distintas cantidades de arena silícea molida empleada como adición en las mezclas cemento 2/arena, las intensidades de los picos mencionadas responden cuantitativamente a la cantidad de arena silícea molida utilizada como adición.

\subsection{Sistemas}

a) Cemento 2/ceniza volante (EN-1)-agua potable filtrada

b) Cemento 2/ceniza volante (EN-1)-agua de mar artificial ASTM

\subsubsection{Evolución de las resistencias mecánicas a flexotracción}

En este apartado se estudia la influencia de la adición de una ceniza volante - seleccionada por sus características de entre diversas cenizas volantes, que se ha designado C.V. (EN-1)- al cemento 2 en su comportamiento mecánico-resistente (a flexotracción) cuando las probetas de mortero (1:3) de $1 \times 1 \times 6 \mathrm{~cm}$ hechas con las mezclas cemento 2/C.V. $(E N-1)=85 / 15,65 / 35,40 / 60$ y $30 / 70$ (en peso) se someten a la acción del agua de mar artificial ASTM y del agua potable filtrada, durante los periodos de tiempo señalados en el apartado 2.2. (hasta 3 años) después del período de curado $(1+21$ dias $)$.

De los resultados correspondientes a la variación de la concentración iónica de los medios de conservación (agua potable filtrada) y de conservaciónataque (agua de mar artificial ASTM), así como de la composición química de las nuevas fases sólidas formadas, de las características estructurales de dichas nuevas fases sólidas y de las fracciones enriquecidas extraídas de las probetas, una vez sometidas a la acción de dichos medios, se dará cuenta en otras publicaciones, del mismo modo que de los estudios realizados con otras dos cenizas volantes y con otros dos cementos portland industriales de características químicas, físicomecánicas y estructurales distintas.

\section{a) Sistemas: cemento 2/C.V. (EN-1)-agua potable filtrada}

En la figura 9 se han representado los valores medios (12 probetas/1 serie/1 cemento ó una mezcla/1 edad) de las resistencias mecánicas a flexotracción, en $\mathrm{kp} / \mathrm{cm}^{2}$, de las series de probetas de mortero (12 probetas/1 serie) hechas con el

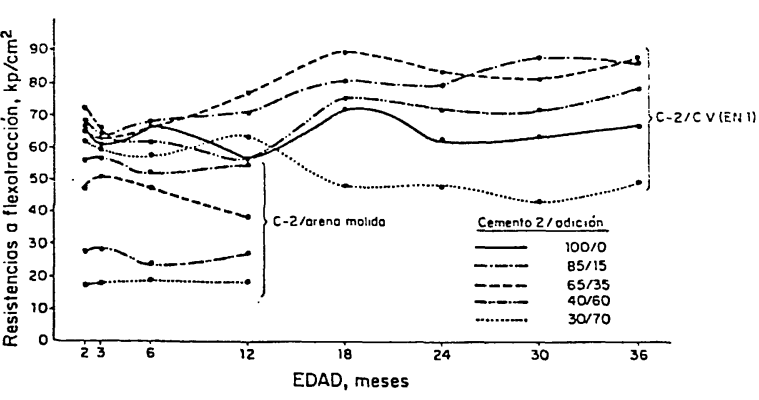

Fig. 9.-Sistemas: cemento 2/adición-agua potable filtrada. Evolución de las resistencias mecánicas, a flexotracción.

cemento 2 y con las mezclas mencionadas cemento $2 /$ ceniza volante (EN-1), en función de los períodos de tiempo de conservación en agua potable filtrada (hasta 3 años), después del período de curado ( 1 +21 días).

En la figura 9 se aprecia que las resistencias mecánicas a flexotracción, que dependen - para un cemento determinado- de las características de la ceniza volante utilizada, se ve influenciada favorablemente por la adición de determinadas cantidades. Así, en este caso, las adiciones del 15, 35 y $60 \%$, en peso, mejoran el comportamiento mecánico-resistente, a flexotracción, del cemento 2 , mientras que la adición del $70 \%$, en peso, produce una disminución de las resistencias mecánicas, a flexotracción, a partir de 12 meses.

De acuerdo con los valores obtenidos con esta ceniza volante - C.V. (EN-1) - y con este cemento - cemento 2-, se puede establecer la siguiente escala:

cemento 2/C.V. (EN-1): 65/35 > 85/15 > $>40 / 60>100 / 0>30 / 70$ (en peso).

Del mismo modo que en el caso de los sistemas cemento 2/escoria -agua potable filtrada y cemento 2/arena molida- agua potable filtrada, las resistencias mecánicas, a flexotracción, de las diversas series de probetas hechas con las distintas mezclas cemento 2/arena molida son menores que las correspondientes a las series de probetas fabricadas con cemento 2 y con sus mezclas con la ceniza volante EN-1; dichas resistencias mecánicas (flexotracción) son tanto menores cuanto mayor es la cantidad de arena silícea molida en la mezcla utilizada para elaborar dichas probetas.

\section{b) Sistemas: cemento 2/C.V. (EN-1)-agua de mar artificial ASTM}

En la figura 10 se han representado los valores medios (12 probetas/1 serie/1 cemento ó 1 mezcla/1 edad) de las resistencias mecánicas, a flexotracción, en $\mathrm{kp} / \mathrm{cm}^{2}$, de las series de probeta de mortero (1:3) hechas con el cemento 2 y con las mezclas reseñadas cemento $2 / \mathrm{C} . \mathrm{V}$. (EN-1) en función de los períodos de tiempo de conservación- 


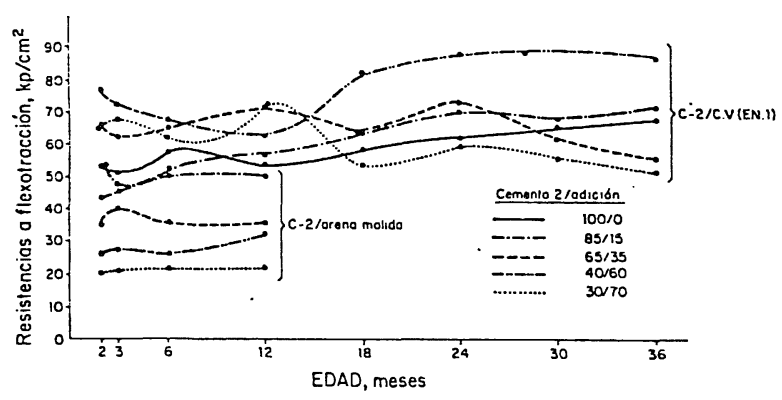

Fig. 10.-Sistemas: cemento 2/adición-agua de mar artificial ASTM. Evolución de las resistencias mecánicas, a flexotracción.

ataque en el agua de mar artificial ASTM (hasta 3 años) después del período de curado $(1+21$ días).

Los valores óptimos de dichas resistencias corresponden a las series de probetas de mortero fabricadas con la mezcla cemento 2/C.V. $(E N-1)=40 / 60$ (en peso) y los valores menores a las elaboradas con la mezcla cemento $2 / \mathrm{C} . \mathrm{V}$. $(E N-1)=30 / 70$, (en peso) a partir de los 18 meses, seguidos de los correspondientes a la mezcla que tiene el $35 \%$ (en peso) de ceniza volante, a partir de los 30 meses.

De las cantidades estudiadas, sólamente la correspondiente a las mezclas cemento $2 / \mathrm{C} . \mathrm{V}$. $(\mathrm{EN}-1)=$ $40 / 60$ (en peso) proporciona, a lo largo de las edades estudiadas, valores superiores que los de las series de probetas de mortero hechas con cemento 2. Las series de probetas de mortero fabricadas con las otras mezclas cemento 2/C.V. (EN-1) proporcionan hasta una edad valores inferiores (como sucede con la que tiene el $15 \%$ de ceniza volante, durante las tres primeras edades: 56,90 y 180 días) y en las restantes valores superiores 0 , por el contrario, proporcionan durante una primera etapa valores superiores y, posteriormente, inferiores (caso de las series de probetas elaboradas con las mezclas cemento 2/C.V. (EN-1) =65/35 y $30 / 70$ (en peso).

En estos sistemas, de acuerdo con los valores obtenidos, se puede establecer la siguiente escala:

cemento 2/C.V. (EN-1): $40 / 60>85 / 15>$

$>100 / 0$ < ó > 65/35 > 30/70 (en peso).

\section{TRABAJOS EN MEDIOS NATURALES}

A la vista de los resultados obtenidos -de los que, en parte, se da cuenta en este trabajo- con diversos cementos de características estructurales distintas y adiciones (una escoria y tres cenizas volantes, en una primera etapa, elegidas por los estudios previos realizados con 19 cenizas volantes) y con el fin de ampliarlos y conocer el comportamiento de los hormigones -a escala realcuando se someten a la acción de medios agresi- vos naturales, se programó la realización de un Proyecto de Investigación a largo plazo (15 años, en una primera etapa, ampliables a 20 si los resultados obtenidos así lo aconsejan), considerando la posibilidad de utilizar en fases sucesivas los cementos que la industria española produzca en cada momento, dedicando un especial interés a los cementos con adiciones, así como a los avances de la tecnología y de los conocimientos en lo que se refiere a la fabricación del hormigón.

De entre los emplazamientos previamente seleccionados, se ha dado preferencia a una Zona de Servicio del Puerto Autónomo de Huelva por las características especiales que tiene (condiciones climáticas, numerosas obras marítimas de hormigón -antiguas y recientes-, aporte de aguas de los ríos Tinto y Odiel, importante zona industrial con eliminación de aguas residuales, etc), en donde, recientemente, se han situado 1.440 probetas de mortero de $4 \times 4 \times 16 \mathrm{~cm}, 1.200$ probetas cilíndricas de hormigón $(\varnothing=15 \mathrm{~cm} \times \mathrm{h}=30 \mathrm{~cm}$ ) y 120 bloques de hormigón armado de 2,00 × 0,50 × 0,50 $\mathrm{m}$ (figura 11), en esta primera etapa, hechos - tanto las probetas, como los bloques-con dos cementos portland industriales de características estructurales distintas, elegidos a partir de las conclusiones obtenidas en los trabajos efectuados a escala de laboratorio y a escala semi-real.

De los resultados obtenidos sobre:

a) Las resistencias mecánicas, a flexotracción y a compresión, de las probetas de mortero sumergidas en agua de mar y en agua potable,

b) las resistencias, a compresión de las probetas de hormigón, sumergidas en el mar y de las probetas de hormigón testigo,

c) las resistencias, a compresión, de las probetas testigo extraidas de los bloques de hormigón situados en la zona de carrera de la marea y del bloque testigo,

que se vienen determinando periódicamente (cada 6 meses morteros y hormigones, y cada 12 los bloques), así como sobre:

d) la composición química y las características estructurales de las fracciones enriquecidas (pasta de cemento), extraídas de las probetas de mortero, de las probetas de hormigón y de las correspondientes probetas testigo de los bloques de hormigón se dará cuenta cuando se tenga información suficiente.

Para realizar este Proyecto de Investigación se ha contado con la valiosa colaboración de los técnicos de la industria del cemento y del hormigón y, de un modo especial, del Puerto Autónomo de Huelva, resaltando la de los Ingenieros D. Joaquín Barba y D. José Luis Reyes, y muy especialmente la del Ing. Director D. Juan Gonzalo y del Presidente del 

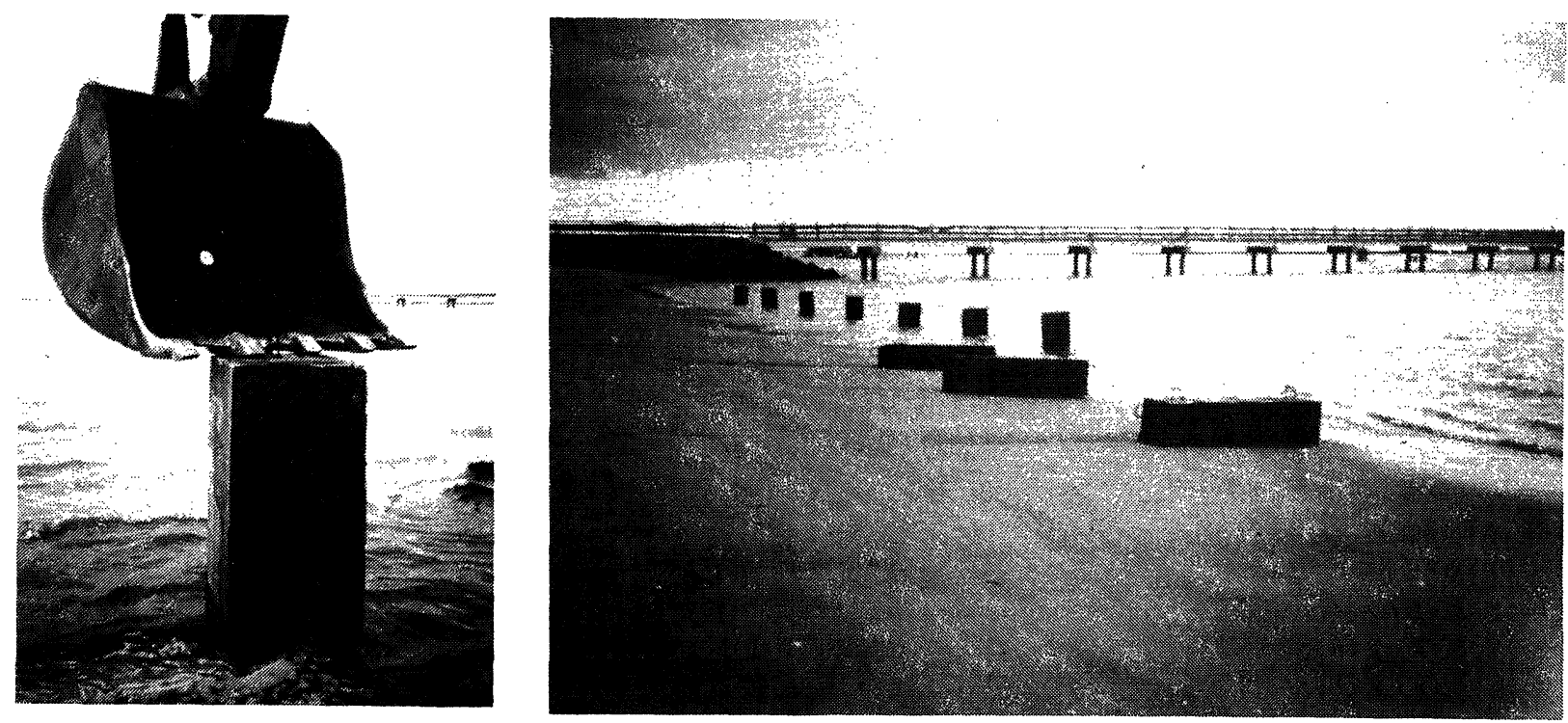

Fig. 11.-Trabajos en agua de mar. Emplazamiento: Puerto autónomo de Huelva.

Consejo de Administración de dicho Puerto D. Juan Arroyo, que - desde el primer momento-pusieron a disposición de este Proyecto sus valiosos conocimientos, así como los medios materiales y humanos que se han precisado, sin los cuales no hubiese sido posible llevarlo a la práctica.

\section{CONCLUSIONES}

\section{Primera}

La adición del 15, 35, 60 y $70 \%$, en peso, de la escoria al cemento portland resistente a los sulfatos, estudiados en este trabajo, favorece su comportamiento mecánico-resistente (a flexotracción), cuando las probetas de mortero (1:3) fabricadas con dicho cemento, y con sus mezclas con la escoria, se someten a la acción del agua potable filtrada y del agua de mar artificial ASTM durante diversos períodos de tiempo (hasta 3 años) después del período de curado $(1+21$ días).

Con todas las mezclas cemento/escoria estudiadas, se ha producido un incremento de las resistencias mecánicas, a flexotracción. Los resultados obtenidos - a lo largo de los tres años experimentadospermiten establecer la siguiente clasificación:

cemento 2/escoria: $30 / 70>65 / 35>40 / 60>$ $>85 / 15>100 / 0$ (en peso),

cemento 2/escoria: $30 / 70>40 / 60>0$ < $65 / 35>$ $>85 / 15>100 / 0$ (en peso),

según que, dichas series de probetas, se hayan sumergido en agua potable filtrada o en agua de mar artificial ASTM.

\section{Segunda}

Las resistencias mecánicas, a flexotracción, de las diversas series de probetas de mortero (1:3) fabricadas con las mezclas cemento 2/arena silícea molida, análogas a las de dicho cemento con la escoria, sumergidas durante diversos períodos de tiempo (hasta 1 año) en los mismos medios después del período de curado, experimentan un descenso - con relación a los valores obtenidos con las probetas hechas con cemento 2-directamente proporcional al contenido de arena silícea molida en dichas mezclas.

\section{Tercera}

La adición de la ceniza volante EN-1 al cemento portland resistente a los sulfatos -estudiados en este trabajo - favorece o perjudica su comportamiento mecánico-resistente (a flexotracción), según las cantidades utilizadas, cuando las probetas de mortero (1:3) hechas con dicho cemento y con sus mezclas con la ceniza volante EN-1 —análogas a las del cemento con la escoria- se sumergen en agua potable filtrada o en agua de mar artificial ASTM, durante diversos períodos de tiempo (hasta 3 años) después del período de curado $(1+21$ días).

Los resultados obtenidos - a lo largo de los tres años- permiten establecer la siguiente clasificación:

cemento 2/C.V. (EN-1): $65 / 35>85 / 15>40 / 60>$ $>100 / 0>30 / 70$ (en peso),

cemento 2/C.V. (EN-1): $40 / 60>85 / 15>100 / 0<6$ $>65 / 35>30 / 70$ (en peso), 
según que se trate de las probetas sumergidas en agua potable filtrada o en agua de mar artificial ASTM.

\section{Cuarta}

Las cantidades de $\mathrm{Ca}$ (II) $<>\mathrm{Ca}(\mathrm{OH})_{2}$ disuelto en los medios en donde han estado sumergidas las diversas series de probetas de mortero hechas con las mezclas cemento 2/escoria - con relación a la correspondiente a las probetas fabricadas con cemento 2- experimentan un descenso, que es función de la mezcla cemento 2/escoria, del tiempo y del medio de conservación (agua potable filtrada - agua de mar artificial ASTM). Por el contrario, dichas cantidades permanecen, prácticamente, constantes - dentro de un entorno- cuando se trata de las series de probetas fabricadas con las mezclas cemento 2/arena silícea molida.

\section{Quinta}

El Mg (II) del agua de mar artificial ASTM -en donde han estado sumergidas las series de probetas de mortero hechas con cemento 2 , con todas las mezclas cemento 2/arena molida y con las que tienen el $15 \%$ (en peso) de escoria - ha desaparecido prácticamente de la disolución, habiendo precipitado como brucita en las probetas y en la disolución.

\section{Sexta}

Cuando se utiliza la escoria o la ceniza volante - estudiadas en este trabajo- como adición al cemento se producen dos efectos, uno de dilución y otro reactivo, en virtud del cual se forman nuevos compuestos como consecuencia de las reacciones que tienen lugar entre la adición y el cemento, mientras que cuando se utiliza la arena silícea molida se produce un efecto de dilución, habiendo favorecido, además, la formación de determinados compuestos en la pasta de cemento (p.e. ettringita, yeso, brucita, etc).

\section{AGRADECIMIENTO}

Nuestro más sincero agradecimiento a las personas del El "Durabilidad del hormigón" del ICCET: Amalia Rodríguez Pereira, Lucila López Solana, M.a Soledad Cid Fernández, Felipe Cantero Palacios y Manuel Cantero Palacios por su valiosa colaboración en la realización de este trabajo.

\section{BIBLIOGRAFIA}

(1) GARPAR-TEBAR, D. (1981): Durabilidad del hormigón. Programa de Investigación del IETcc. Informes de la Construcción, 330, 41-50.

(2) GARCIA DE PAREDES, P. (1967): Inalterabilidad de los conglomerantes al ataque de los sulfatos. Comparación de métodos para apreciarla. Cuadernos de Investigación del IETcc (Madrid), pp. 11-14.

(3) BICZOK, I. (1972): Corrosión y Protección del Hormigón. Edit. Urmo, Bilbao, pag. 211.

(4) GASPAR-TEBAR, D. y SAGRERA-MORENO, J. L. (1982): Resistencia química del hormigón. XVIII. Acción del agua de mar: influencia de la adición de escoria a un cemento portland resistente al yeso. Estudio por DRX. Materiales de Construcción, 188, 37-58.

(5) GASPAR-TEBAR, D. y SAGRERA-MORENO, J. L. (1986): Resistencia química del hormigón. XXIV. Influencia de la adición de escoria a un cemento portland resistente al yeso. Estudio de la concentración iónica del sistema cemento 2/escoria -agua de mar artificial-. Materiales de Construcción, 196, 49-66.

(6) GASPAR-TEBAR, D. y SAGRERA-MORENO, J. L. (1981): Resistencia química del hormigón. X. Influencia de la adición de escoria a un cemento portland resistente al yeso. Estudio por DRX del sistema cemento 2/escoria -agua potable filtradaMateriales de Construcción, 182, 11-22. 